\title{
BMJ Global Health Can lay health workers support the management of hypertension? Findings of a cluster randomised trial in South Africa
}

\author{
Jane Goudge, ${ }^{1}$ Tobias Chirwa, ${ }^{2}$ Sandra Eldridge, ${ }^{3}$ Francesc Xavier F Gómez-Olivé, ${ }^{4}$ \\ Chodziwadziwa Kabudula, ${ }^{4}$ Felix Limbani, ${ }^{1}$ Eustasius Musenge, ${ }^{6}$ \\ Margaret Thorogood ${ }^{2,5}$
}

To cite: Goudge J, Chirwa T, Eldridge $\mathrm{S}$, et al. Can lay health workers support the management of hypertension? Findings of a cluster randomised trial in South Africa. BMJ Glob Health 2018;3:e000577. doi:10.1136/ bmjgh-2017-000577

Handling editor Valery Ridde

- Additional material is published online only. To view please visit the journal online (http://dx.doi.org/10.1136/ bmjgh-2017-000577).

Received 19 September 2017 Revised 15 November 2017 Accepted 24 November 2017

Check for updates

For numbered affiliations see end of article.

Correspondence to Professor Jane Goudge; Jane.goudge@gmail.com

\section{ABSTRACT}

Introduction In low/middle-income countries with substantial HIV and tuberculosis epidemics, health services often neglect other highly prevalent chronic conditions, such as hypertension, which as a result are poorly managed. This paper reports on a study to assess the effect on hypertension management of lay health workers (LHW) working in South African rural primary healthcare clinics to support the provision of integrated chronic care. Methods A pragmatic cluster randomised trial with a process evaluation in eight rural clinics assessed the effect of adding two LHWs supporting nurses in providing chronic disease care in each intervention clinic over 18 months. Control clinics continued with usual care. The main outcome measure was the change in the difference of percentage of clinic users who had elevated cardiovascular risk associated with high blood pressure (BP) before and after the intervention, as measured by two cross-sectional population surveys.

Results There was no improvement in BP control among users of intervention clinics as compared with control clinics. However, the LHWs improved clinic functioning, including overall attendance, and attendance on the correct day. All clinics faced numerous challenges, including rapidly increasing number of users of chronic care, unreliable BP machines and cuffs, intermittent drug shortages and insufficient space.

Conclusion LHWs improved the process of providing care but improved BP control required improved clinical care by nurses which was compromised by large and increasing numbers of patients, the dominance of the vertically funded HIV programme and the poor standards of equipment in clinics.

Trial registration number ISRCTN12128227.

\section{INTRODUCTION}

Low/middle-income countries are facing an increasing burden of chronic non-communicable diseases, including a high prevalence of hypertension. ${ }^{1}$ In countries with high levels of HIV and tuberculosis (TB), the result is a considerable burden of care in primary healthcare clinics. In South Africa, the health service is managing the world's largest HIV treatment programme, ${ }^{2}$ but hypertension, which is more prevalent than HIV, is poorly managed with low levels of awareness and control. $^{3}{ }^{4}$ In the Agincourt Health and Demographic Surveillance System (HDSS) site, based in rural north-east South Africa, around $57 \%$ of the adult population have high blood pressure (BP), but the condition is appropriately managed in less than $10 \% .^{5}$

Primary healthcare clinics in South Africa are responsible for case finding, treatment and adherence support for patients with chronic diseases. In an effort to provide integrated care for the large number of patients with chronic disease, services have recently been reorganised with appointment scheduling, preappointment retrieval of files and preparing medication prior to the patient's appointment. $^{6-8}$ The aim is to speed the journey for chronic patients through the clinic, improving efficiency, while ensuring chronic conditions are effectively controlled. A recently published review of these changes showed that nurses were struggling to carry out these tasks in addition to clinic consultations. $^{9}$

Task shifting has been an important strategy in the provision of care for patients with HIV and TB. ${ }^{10}$ Lay counsellors provide counselling and testing services, ${ }^{11-14}$ and lay health workers (LHW) provide adherence support. ${ }^{15-17}$ We hypothesised that LHWs would be able to assist clinic staff with the administrative and education aspects of the newly reorganised integrated chronic care, allowing the nurses to focus on the clinical consultations and hence leading to improve health outcomes. In this paper, we report the results of a parallel cluster randomised trial 


\section{Key questions}

\section{What is already known about this topic?}

- Systematic reviews have provided evidence of the effectiveness of lay health workers (LHW) in improving access to care, the quality of care, including screening for cardiovascular risk factors, reducing systolic blood pressure (BP), fasting blood glucose and weight, as part of community-based care.

- While there is systematic review of studies looking at the effect of task shifting, the focus was shifting prescribing from doctors to nurses, we found no trials looking at LHWs' role in the provision of clinic-based integrated chronic care.

\section{What are the new findings?}

- The Nkateko study was the first randomised controlled trial to assess the role of LHWs in the provision of integrated chronic care.

- While we found no improvement in BP control, the LHWs improved clinic attendance.

- A large and increasing numbers of patients, the dominance of the vertically funded HIV programme and the poor standards of equipment in clinics compromised the quality of clinical care provided by nurses.

- Assistance from LHWs with booking appointments, sending reminders, prepacking medication and providing health education was insufficient to improve BP control in this environment.

\section{Recommendations for policy}

- Our results, taken together with the existing evidence, suggest that LHWs can play an important role in supporting the provision of integrated chronic care.

- However, adding additional human resources (even if readily available and relatively inexpensive) is unlikely to have an effect on health outcomes, without the necessary equipment to accurately measure BP, and sufficient clinical staff to treat the growing numbers of chronic patients.

which tested a clinic-level intervention, shifting tasks from nurses to LHWs. We aimed to improve the management of chronic conditions, specifically the management of hypertension.

\section{METHODS \\ Study setting}

The trial was based in Bushbuckridge subdistrict in Mpumalanga Province, South Africa, where the MRC/ Wits Rural Public Health and Health Transitions Research Unit has been running the Agincourt HDSS since $1992 .{ }^{18}$ The Agincourt HDSS, covering an area of $450 \mathrm{~km}^{2}$, includes 115000 individuals living in approximately 20000 households distributed in 32 villages. The area has high unemployment with more than $50 \%$ of men (aged between 25 and 54 years old) and more than $20 \%$ of women (25-49 years old) migrating to urban areas for work for part of the year. ${ }^{19}$ Infrastructure has improved in the last few years, but there is still irregular water supply, electricity is unaffordable for many, and the schools and health facilities do not provide services of adequate quality. ${ }^{18}$
Ten primary healthcare facilities and three hospitals that are 25-60 km away from the site serve the local population. The Department of Health piloted the provision of integrated chronic disease care (ICDM) in the Bushbuckridge subdistrict, 2 years prior to the start of this study. It has since been rolled out to other provinces.

\section{Study design, randomisation and blinding}

The study was a pragmatic cluster randomised controlled trial with repeated cross-sectional surveys. ${ }^{20}{ }^{21}$ Each cluster was one clinic together with the population that it served. Clinics were included if they were located in the site, rather than on the periphery, and if the clinic manager consented to participate in the study (figure 1). A clinic located out of the study site was chosen as a pilot site, to learn lessons about implementing the intervention prior to establishing it in the trial sites. Simple 1:1 random allocation of the eight clinics was carried out at a public meeting in the presence of clinic staff and community members. Clinics' names in sealed envelopes were drawn from a box by a community member. This transparent process facilitated understanding and trust in the randomisation. It was not possible to blind clinic staff or patients to the allocation. However, the primary outcome was measured using an encrypted data set, with no indication of which arm received the intervention.

\section{Usual care in the study site}

On attending a clinic, each patient is assigned to one of two queues, one for patients with an ongoing chronic condition, another for the remaining patients. After obtaining his/her file, each patient has their temperature, pulse, weight and BP measured at a 'vital signs' station. This is usually carried out by a junior (enrolled) nurse, before the patient is seen by a professional nurse, who diagnoses, prescribes and dispenses medication in a designated chronic care consultation room. The operation of the separate chronic disease pathway depends on sufficient staff and equipment to maintain two vital signs stations (one for each queue), to carry out the additional tasks (preappointment retrieval of files, appointment scheduling and predispensing of medication), and that patients come within a few days of their appointed day, otherwise prepacked medication has to be unpacked.

\section{Intervention}

The intervention consisted of two LHWs assigned to each clinic to support nurses in the management of patients with chronic disease. The LHWs, selected from the local community, had completed their secondary education but had had little further education. They were trained and supervised by an implementation manager, who was a local primary healthcare nurse, with a training qualification. As part of the pragmatic design, the staff and supervisors of intervention clinics were able to decide which tasks the LHWs should do. All the intervention clinics chose to have the LHWs assisting with booking appointments, retrieving and filing patient files, and 


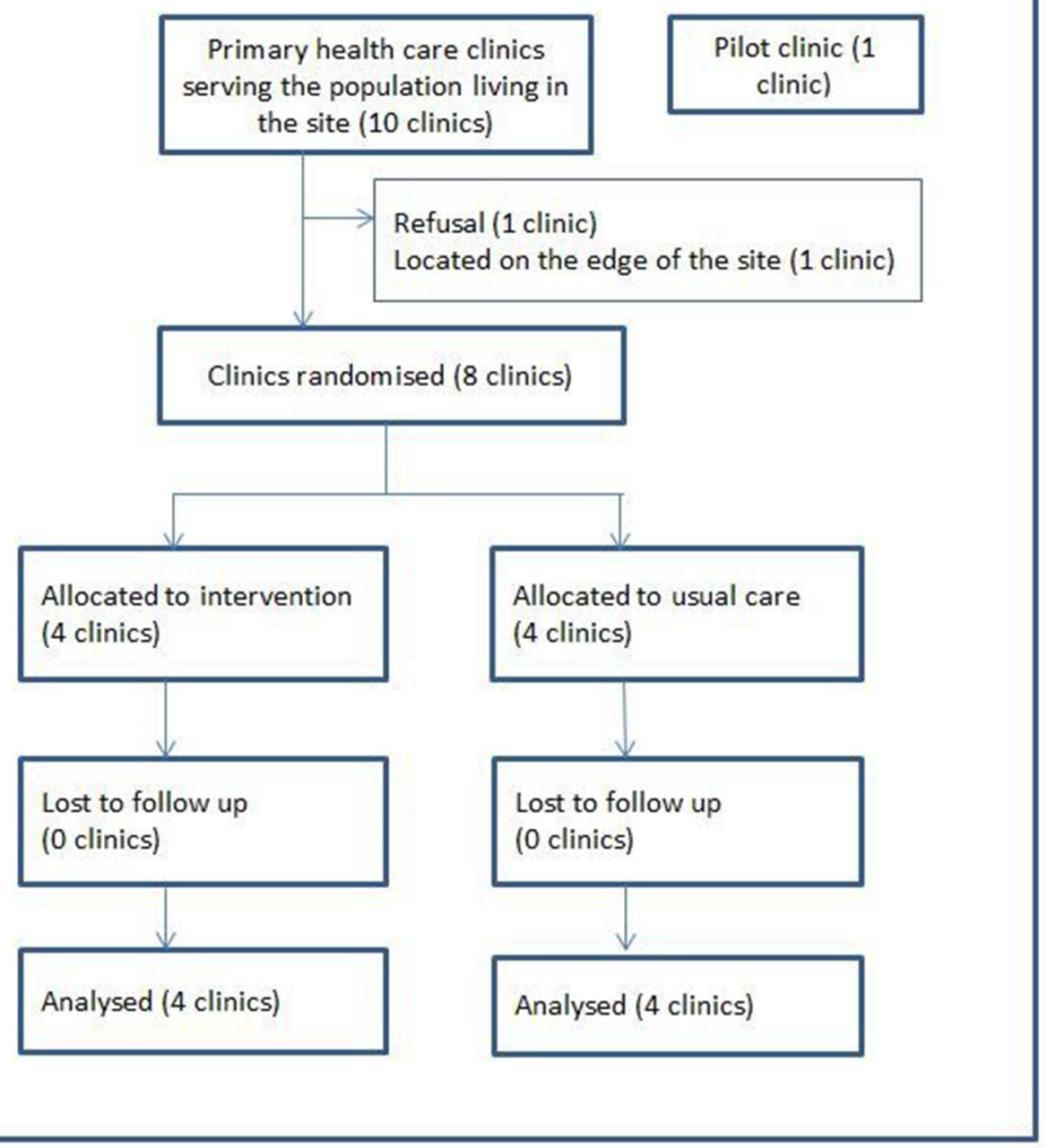

Figure 1 Allocation of clinics.

providing health education (on adherence and lifestyle). They also all chose to have the LHWs taking measurements in the vital signs queue and assisting the nurses with the prepacking of medications. Some clinics struggled to find space for these activities to take place, so the LHWs often had to operate in the corridor or the reception area. In addition, the LHWs phoned or sent a text message to patients with hypertension to remind them of their appointment. The implementation manager ensured fidelity to the planned intervention. The four control clinics continued working as normal and the implementation manager did not visit them or interact with their staff to avoid contamination.

In the first months of the intervention, the implementation manager found that none of the intervention clinics had cuffs in good repair for the electronic BP machines. Without the possibility of correctly measuring BP the intervention had little chance to be effective. Thus, although this was a pragmatic trial, we decided that it was necessary to replace the cuffs. To keep the comparison meaningful, we provided both the intervention and control clinics with two new sets of cuffs. We originally planned the intervention to last for 15 months, but after having replaced the cuffs, we extended the intervention period for a further 3 months, up to 18 months in total.

\section{Primary and secondary outcomes}

Our primary outcome was based on the South African guidelines for the management of hypertension, which call for a focus on people at moderate or greater cardiovascular risk. ${ }^{22}$ The primary outcome is defined as the difference (between intervention and control clinics) in the change of the proportion of the population who have uncontrolled hypertension together with a risk profile indicating at least moderate risk of cardiovascular disease (CVD).$^{20}$ We did not have the resources to make the clinical diagnoses called for in the guidelines and used proxy measures for some items. For example, we collected data on self-reported stroke rather than making a diagnosis, and we used waist circumference as a proxy measure of obesity. The participants whose data were used to calculate the outcome measures were the self-defined users of one of the eight clinics. As there were no records of who attended a clinic, and individuals are free to attend any clinic they choose, we asked respondents 
Box 1 Secondary outcomes of the trial as reported in this paper

Secondary outcomes derived from population surveys

1. Changes in the proportion of the population at different levels of blood pressure-related cardiovascular risk by age group and sex.

2. Change in proportion of the population with undiagnosed hypertension.

3. Change in the proportion of the population reporting they had had their blood pressure measured.

4. Change in the proportion of the population reporting that they are using medication for hypertension.

5. Change in the proportion of people in the population reporting that they have attended a clinic in the last year. Listed in the analysis plan but not collected.

Secondary outcomes derived from clinic activity data

6. Retention in care of people with diagnosed hypertension defined by the proportion of appointments kept during the study period.

7. The number of clinic visits per month related to a diagnosis of hypertension. Not listed in the analysis plan but used to replace secondary outcome no. 5 above.

which was their usual clinic and which clinic they visited last. For the large majority of respondents the usual clinic was the same as the last clinic. We used the usual clinic for the analysis of the primary outcome.

Our secondary outcomes are listed in box 1 . The first five were derived from the two population surveys, while the last two came from the data we collected from patients as they entered the clinics, and from their clinic files. Data for the fifth outcome were not collected, as the time frame of 1 year was omitted from the survey questionnaire. There was some delay in setting up the system for collecting clinic data; as a result, the last two outcomes are reported for the period May 2014 to July 2015.

\section{Baseline and end of intervention cross-sectional surveys}

For the two surveys, a separate random weighted sample of people over 18 years was drawn from the Agincourt census database with no knowledge of which, if any, clinic individuals used. In the first survey, no other eligibility criterion was used. In the second survey, we excluded from the sampling frame individuals who had recently been randomly selected to participate in another research study that demanded a lot of participants' time. The sample was weighted to provide larger numbers of older people, who could be expected to have a higher prevalence of hypertension. Informed consent was sought from each participant and refusals are reported in figure 2.

Fieldworkers were trained for 2 weeks before the survey. As the fieldworkers lived in the community it was not possible to blind them to which clinics received the intervention. However, they had no involvement in either the implementation or the process evaluation. The questionnaire was piloted in advance. Quality control included three stages in the first survey: a supervisor checked the completed questionnaires in the field; the project manager checked them as he filed them in the office; and the data manager checked them prior to data entry. In the second survey, we included an additional check of a random $5 \%$ of interviews for which a supervisor returned to the household a few days later and reinterviewed the participant to confirm responses to some selected questions. A double entry data system was used and a data manager made the comparison of the two entries and corrected those where there was a discrepancy using the paper questionnaire as a reference.

The questionnaire included self-reported history of hypertension, diabetes, stroke, heart failure, angina and heart attacks, smoking, clinic use (last and usual) and family history of CVD. We did not attempt to measure the number of cigarettes smoked as regular heavy smoking is unusual in this cash-poor community. Information on age, gender, marital status, education and socioeconomic status was drawn from the census database.

\section{Variable measurement and definitions}

Pulse, systolic and diastolic BP was measured three times in a seated position after $5 \mathrm{~min}$ of rest and with $2 \mathrm{~min}$ interval using the OMRON M6W automated cuff (Omron, Kyoto, Japan). Waist circumference was measured using a flexible tape measure (SECA). A finger prick was used to measure random blood glucose (CareSens N Monitor) and total cholesterol (CardioChek PA Silver version).

We derived the mean systolic and diastolic BP using the average of the second and third BP measurements. We defined diabetes as a random glucose measure of over $11 \mathrm{mmol} / \mathrm{L}$. A person with a random glucose measure between 7 and $11 \mathrm{mmol} / \mathrm{L}$, and who reported that they had not eaten for 12 hours, was recorded as having high blood glucose. The remaining respondents were considered not to be diabetic. We defined obesity as a waist circumference greater than $94 \mathrm{~cm}$ in men or greater than $80 \mathrm{~cm}$ in women. ${ }^{22}$

We estimated the time that patients spent in the clinics by calculating the difference between the time the patients reported arriving at the clinics and the time of the exit interviews, as described under the Process evaluation section.

\section{Clinic activity data}

To collect data on clinic activity, an experienced data entry clerk sat with a laptop in each control and intervention clinic for the period of the intervention. A unique record using identifiers (ID numbers, cellphone, date of birth, gender, village of residence and the name of another person in the household) was created for each consenting individual, and the date of visit, diagnosis and date of return visit were then collected from the clinic records for this and all subsequent visits by that individual. ${ }^{23}$

\section{Sample size}

We derived our assumptions for the sample size calculation from data collected in the same site in $2010 .{ }^{24} \mathrm{We}$ adopted the use of the coefficient of variation (SD of the cluster means divided by the overall mean) as used 


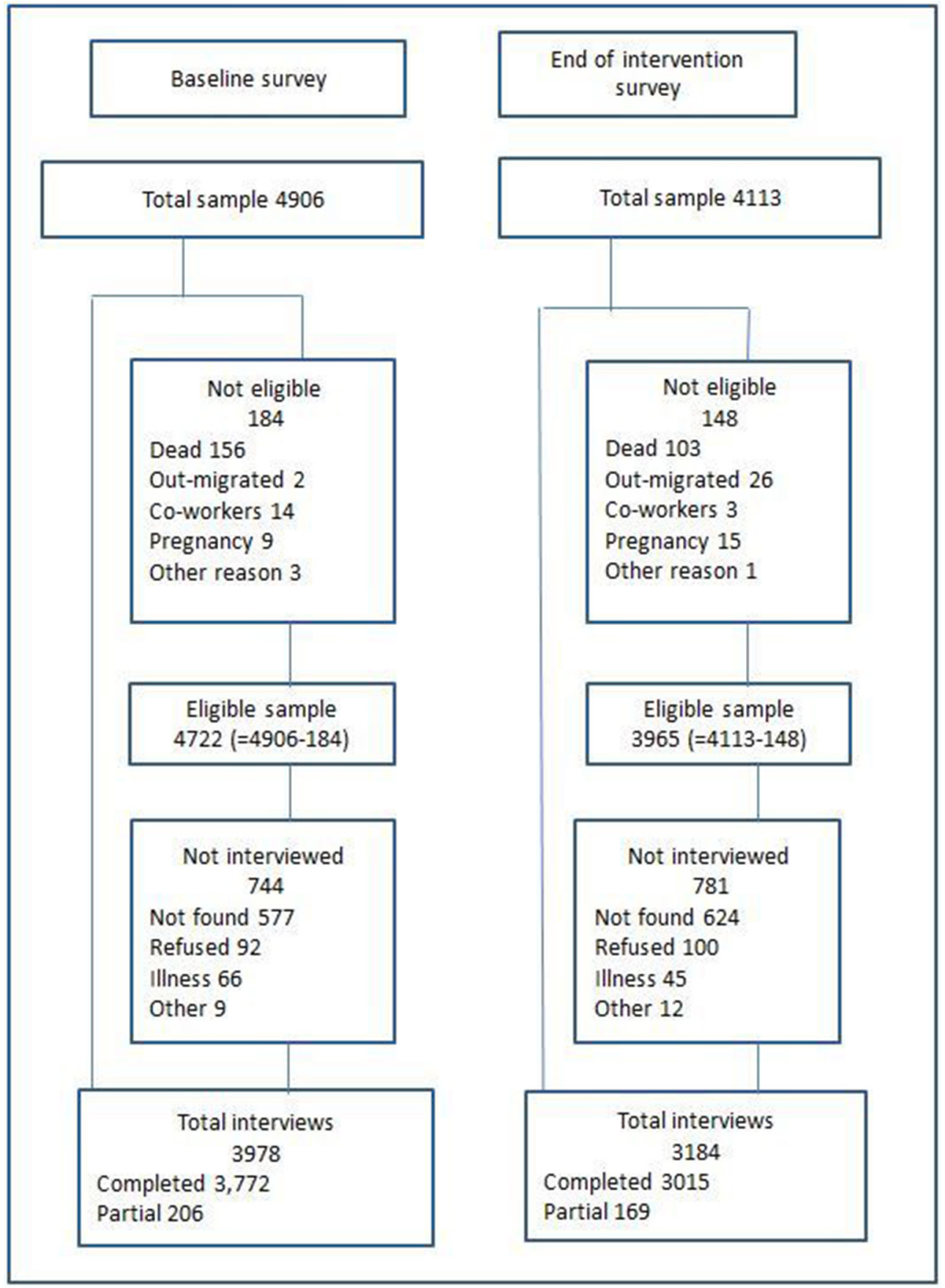

Figure 2 Response to survey by individuals sampled.

in similar study settings when we cannot get a good intracluster variation ${ }^{25-27}$ and assumed that the coefficient of variation would be similar in the two groups and that effects of the interventions would be similar across clusters. We used a background prevalence of $36 \%$ and a coefficient of variation of $0.132(95 \%$ CI 0.087 to 0.177 ). We assumed that the two population surveys would each include at least 4000 participants, with approximately 500 people in each of the eight clusters. We estimated that we would have $88 \%$ power to detect a reduction of $11 \%$ (from $36 \%$ to $25 \%$ ) in people at moderate or greater cardiovascular risk.

\section{Statistical methods}

Sociodemographic and clinical information including both primary and secondary outcomes was summarised using frequencies and summary measures. Continuous variables such as age and BP levels were summarised using the mean and SD. Categorical variables such as gender were described through frequency tabulations by reporting the relative percentage and the number of observations $(\%, \mathrm{n})$.

The analysis of the primary outcome was conducted to test the difference in the change in the proportions with moderate or greater added risk of CVD in the 
intervention and control clusters. We used the cluster adjusted Pearson's $\chi^{2}$ to adjust for clustering for each group. This analysis was carried out in EXCEL with user written commands. All other analyses were done using STATA V.14 (StataCorp, 2015. Stata Statistical Software: Release 14. College Station, TX: StataCorp) and statistical significance was considered at $5 \%$ level.

We included the following sensitivity analyses for the primary outcome: (A) an analysis which included those who did not name any specific drugs when reporting on hypertensive drugs (in the primary analysis these individuals were not included as having hypertension); (B) an analysis using the 'last' clinic rather than the 'usual' clinic to assign individuals to clinics; (C) an analysis using two-stage regression modelling instead of the adjusted $\chi^{2}$; and (D) an analysis using mixed effects model adjusting for covariates. Secondary outcomes were analysed in the same way as the primary outcome. No sensitivity analyses were conducted.

\section{Process evaluation}

We conducted a theory-driven, mixed methods evaluation to understand the causal processes that led to change (or not). ${ }^{20}$ We observed clinic activity, the movement of patients along the clinic pathway and patient consultations over a period of 3-9 days at 6-month intervals (control and intervention) during the 18-month intervention period. We conducted brief exit interviews with the patients as they left the clinic $(n=703)$. We also conducted bimonthly interviews with the LHWs throughout the intervention, as well as interviews with clinic staff, and clinic and district managers.

The clinic managers of all the clinics taking part in the trial consented for their clinic staff to participate and all individuals interviewed in the population surveys or process evaluation gave written informed consent to the interview.

\section{Role of funding source}

The funder had no involvement in the study.

\section{RESULTS}

The baseline population survey collected information on 3978 people, with a response rate of $84.2 \%$ (3978/4722) (figure 2). After excluding 44 questionnaires that were completed by a fieldworker who was later found to be unreliable, 145 respondents who reported that they did not use any public clinic and a further 376 respondents who used a clinic that was not one of the trial clinics, 3413 questionnaires were included in the analysis. The end of intervention survey had a response rate of $80.3 \%$ (3184/3965) (figure 2). After excluding those who reported that they did not use public clinics (97) and those who did not use one of the trial clinics (548), 2539 questionnaires were included in the analysis.

There were no important differences in sociodemographic or health variables between the control and intervention groups (table 1). Just under half of the respondents were found to have hypertension. In $6 \%-10 \%$ the hypertension was controlled on treatment, $9 \%-13 \%$ were on treatment but the hypertension was not controlled, and between $20 \%$ and $30 \%$ of the respondents had hypertension but were not on treatment. As is common in the black South African population, obesity was more prevalent in women than men. There are fewer men aged over 80 years in the second survey because we excluded individuals who had just participated in another research study. This resulted in a very small sampling frame for this small group of men, and so we selected for interview all the available men.

When we planned the study, we were concerned that many individuals might move between intervention and control clinics and so we asked respondents which was their usual clinic and which was the last clinic they used. We found that less than $3.5 \%$ of individuals had switched between intervention and control clinics (see online supplementary table 1).

\section{Primary and secondary outcomes}

There was no evidence of an effect of the intervention in the primary outcome or in the first four secondary outcomes that were derived from the population surveys (table 2). None of the sensitivity analyses altered this conclusion. There was no evidence of a reduction in those with moderate or greater CVD risk (OR 1.13, 95\% CI 0.83 to 1.54 ). The $95 \%$ CI excluded the OR of 0.59 given by the clinically important difference in our sample size calculation, providing very strong evidence that the intervention as delivered could not have achieved the desired change. By the end of the intervention, three quarters of patients with hypertension were attending the intervention clinics on the day of their appointment, compared with $56 \%$ in control clinics (figure 3), suggesting improved adherence.

All clinics experienced an increase in the number of visits by patients with a chronic condition (figure 4) (analysis of variance coefficient $53.3 ; \mathrm{P}<0.01$ ). The number of visits in control clinics was similar for those with and without hypertension. However, in the intervention clinics the number of visits by chronic patients (with and without hypertension) was greater than in the control clinics (figure 4). In particular, there were a significantly greater number of hypertension visits than other chronic condition visits in the intervention clinics (analysis of variance for patient with hypertension coefficient 1295; $\mathrm{P}<0.01$, chronic conditions coefficient 463; $\mathrm{P}<0.01$ ).

\section{Process evaluation}

The almost doubling of the number of patients with a chronic disease attending the clinics over the 18 months of the study, with no matching increase in equipment or space, resulted in both control and intervention clinics facing numerous challenges. These included BP machines that often failed to function, worn out cuffs, intermittent shortages of drugs and insufficient space for the increasing numbers of patients. The cuffs that we 
Table 1 Sociodemographic and health variables in the baseline and end of intervention surveys

\begin{tabular}{|c|c|c|c|c|}
\hline & \multicolumn{2}{|l|}{ Control } & \multicolumn{2}{|l|}{ Intervention } \\
\hline & $\begin{array}{l}\text { Baseline survey } \\
n=1908\end{array}$ & $\begin{array}{l}\text { End of intervention } \\
\text { survey } \\
n=1430\end{array}$ & $\begin{array}{l}\text { Baseline survey } \\
n=1505\end{array}$ & $\begin{array}{l}\text { End of intervention } \\
\text { survey } \\
n=1109\end{array}$ \\
\hline \multirow[t]{2}{*}{ Mean age (SD) } & $56.4(19.8)$ & $52.7(19.7)$ & $56.8(18.9)$ & $53.0(19.2)$ \\
\hline & $\%$ (n) & $\%$ (n) & $\%$ (n) & $\%$ (n) \\
\hline Female & $56.0(1068)$ & $70.5(1008)$ & $55.1(829)$ & 68.7 (762) \\
\hline \multicolumn{5}{|l|}{ Education } \\
\hline No education & 40.6 (772) & $37.2(530)$ & $38.4(576)$ & $32.3(357)$ \\
\hline Primary & $25.4(483)$ & $21.7(310)$ & 25.4 (381) & $21.9(242)$ \\
\hline Secondary & $30.9(588)$ & $38.6(550)$ & $31.9(479)$ & $40.7(451)$ \\
\hline 2 & $20.1(348)$ & 20.7 (292) & $18.3(253)$ & $18.9(209)$ \\
\hline 3 & 19.2 (332) & $18(254)$ & $19(263)$ & 20.7 (229) \\
\hline 4 & $19.4(335)$ & $19.6(277)$ & $20.8(288)$ & $20.8(230)$ \\
\hline 5 (highest) & $22.5(390)$ & $18.1(256)$ & 25.4 (351) & 24.7 (273) \\
\hline \multicolumn{5}{|l|}{ Smoking history } \\
\hline Never smoked & $79.3(1507)$ & $84.9(1214)$ & $76.8(1151)$ & 85.8 (952) \\
\hline Previous smoker & $11.3(214)$ & $5.6(80)$ & $13.4(201)$ & $7(78)$ \\
\hline Smokes $<1 /$ day & $2.3(44)$ & $2(29)$ & $2.4(36)$ & $1.6(18)$ \\
\hline Smokes >1/day & $7.2(136)$ & $7.5(107)$ & $7.4(111)$ & $5.5(61)$ \\
\hline Heart failure & $2.8(53)$ & $1.5(21)$ & $2.4(36)$ & $1.2(13)$ \\
\hline \multicolumn{5}{|l|}{ Obesity } \\
\hline Male (waist >94 cm) & $26.3(221)$ & $20.4(86)$ & $31.1(210)$ & $30.3(105)$ \\
\hline Female (waist $>80 \mathrm{~cm}$ ) & $80.2(857)$ & $78.5(791)$ & $81.4(675)$ & $77.3(589)$ \\
\hline \multicolumn{5}{|l|}{ Hypertension } \\
\hline No hypertension & $53.7(1024)$ & $52.9(757)$ & $53.0(797)$ & $50.9(564)$ \\
\hline On treatment and controlled & $10.2(194)$ & $11.2(160)$ & $6.6(100)$ & $11.3(125)$ \\
\hline On treatment but not controlled & $9.2(175)$ & $13.2(189)$ & $8.8(133)$ & $13.0(144)$ \\
\hline Not on treatment & $27.0(515)$ & 22.7 (324) & $31.6(475)$ & $24.9(276)$ \\
\hline \multicolumn{5}{|l|}{ Blood glucose } \\
\hline Normal $<11$, not fasting & $91.5(1745)$ & $92.7(1325)$ & $91.4(1375)$ & $92.1(1021)$ \\
\hline High $7<11$, fasting & $0.7(13)$ & $0.9(13)$ & $0.3(4)$ & $0.8(9)$ \\
\hline Diabetic 11 or more & $7.8(149)$ & $6.4(92)$ & $8.4(126)$ & $7.1(79)$ \\
\hline
\end{tabular}

CVD, cardiovascular disease; TIA, transient ischaemic attack.

replaced early on in the trial were worn out before the end of the intervention. There was no routine servicing of the BP machines, and when they were taken for repair, they could be away from the clinic for several months.
Sometimes a clinic only had functioning mercury sphygmomanometers, which the nurses were reluctant to use because of the time involved and the discomfort of using stethoscopes for several hours at a time. Table 3 provides 
Table 2 Comparison of primary and secondary outcomes at end of intervention by study arm

\begin{tabular}{|c|c|c|c|c|c|c|}
\hline & $\begin{array}{l}\begin{array}{l}\text { Control } \\
n=1414\end{array} \\
\end{array}$ & $\begin{array}{l}\text { Intervention } \\
\mathrm{n}=1094\end{array}$ & Estimated & Adjusted OR & Adjusted $\chi^{2}$ & \\
\hline & $\%(n)$ & $\%(n)$ & ICC & $(95 \% \mathrm{Cl})$ & & $P$ value \\
\hline CVD risk & & & & & & \\
\hline No or low & $74.1(1048)$ & $73.2(801)$ & 0.006 & $1.13(0.83$ to 1.54$)$ & 0.076 & 0.782 \\
\hline Moderate or higher & $25.9(366)$ & $26.8(293)$ & & & & \\
\hline Gender & & & & & & \\
\hline Female & & & & & & \\
\hline No or low & $74.2(742)$ & $74.8(564)$ & 0.004 & $1.00(0.75$ to 1.34$)$ & 0.039 & 0.844 \\
\hline Moderate or higher & $25.8(258)$ & $25.2(190)$ & & & & \\
\hline Male & & & & & & \\
\hline No or low & 73.9 (306) & 69.7 (237) & 0.013 & 1.32 (0.85 to 2.04$)$ & 0.59 & 0.443 \\
\hline Moderate or higher & $26.1(108)$ & $30.3(103)$ & & & & \\
\hline Age & & & & & & \\
\hline 18-29years & & & & & & \\
\hline No or low & $99.0(188)$ & 95.9 (117) & 0.183 & $22.5(0.122$ to 4.144$)$ & 0.3 & 0.584 \\
\hline Moderate or higher & $1.1(2)$ & $4.1(5)$ & & & & \\
\hline 30-39years & & & & & & \\
\hline No or low & $90(206)$ & $89.6(173)$ & $<0.001$ & 1.04 (0.55 to 1.95$)$ & 0.012 & 0.914 \\
\hline Moderate or higher & $10(23)$ & $10.4(20)$ & & & & \\
\hline 40-49years & & & & & & \\
\hline No or low & $87.2(224)$ & $84.8(167)$ & $<0.001$ & 1.22 (0.72 to 2.08$)$ & 0.532 & 0.466 \\
\hline Moderate or higher & $12.8(33)$ & $15.2(30)$ & & & & \\
\hline 50-59 years & & & & & & \\
\hline No or low & $75.1(148)$ & $77.3(136)$ & 0.004 & 0.88 (0.50 to 1.54$)$ & 0.186 & 0.666 \\
\hline Moderate or higher & $24.9(49)$ & $22.7(40)$ & & & & \\
\hline 60-69years & & & & & & \\
\hline No or low & $67.3(142)$ & $68.0(106)$ & 0.012 & 0.97 (0.62 to 1.51$)$ & 0.01 & 0.92 \\
\hline Moderate or higher & 32.7 (69) & $32.0(50)$ & & & & \\
\hline 70-79years & & & & & & \\
\hline No or low & $44.1(82)$ & $47.4(64)$ & 0.037 & 0.88 (0.43 to 1.77$)$ & 0.125 & 0.723 \\
\hline Moderate or higher & $55.9(104)$ & $52.6(71)$ & & & & \\
\hline $80+$ years & & & & & & \\
\hline No or low & $40.3(58)$ & $33.0(38)$ & $<0.001$ & 1.37 (0.82 to 2.28$)$ & 1.435 & 0.231 \\
\hline Moderate or higher & $59.7(86)$ & $67.0(77)$ & & & & \\
\hline Hypertension diagnosis & & & & & & \\
\hline Undiagnosed & $22.1(312)$ & $24.1(264)$ & & 1.12 (0.93 to 1.35$)$ & & \\
\hline None or diagnosed & $77.9(1102)$ & 75.9 (830) & $<0.001$ & & 1.489 & 0.222 \\
\hline BP ever measured & & & & & & \\
\hline No & $5.7(80)$ & $9.1(100)$ & 0.014 & $0.71(0.29$ to 1.73$)$ & 1.729 & 0.188 \\
\hline Yes & $94.3(1334)$ & 90.7 (994) & & & & \\
\hline Taking medication for hy & & & & & & \\
\hline No & $75.6(1069)$ & $75.7(828)$ & 0.024 & 1.21 (0.70 to 2.09$)$ & 0.002 & 0.988 \\
\hline Yes & $24.4(345)$ & $24.3(266)$ & & & & \\
\hline
\end{tabular}

BP, blood pressure; CVD, cardiovascular disease; ICC, intraclass correlation. 


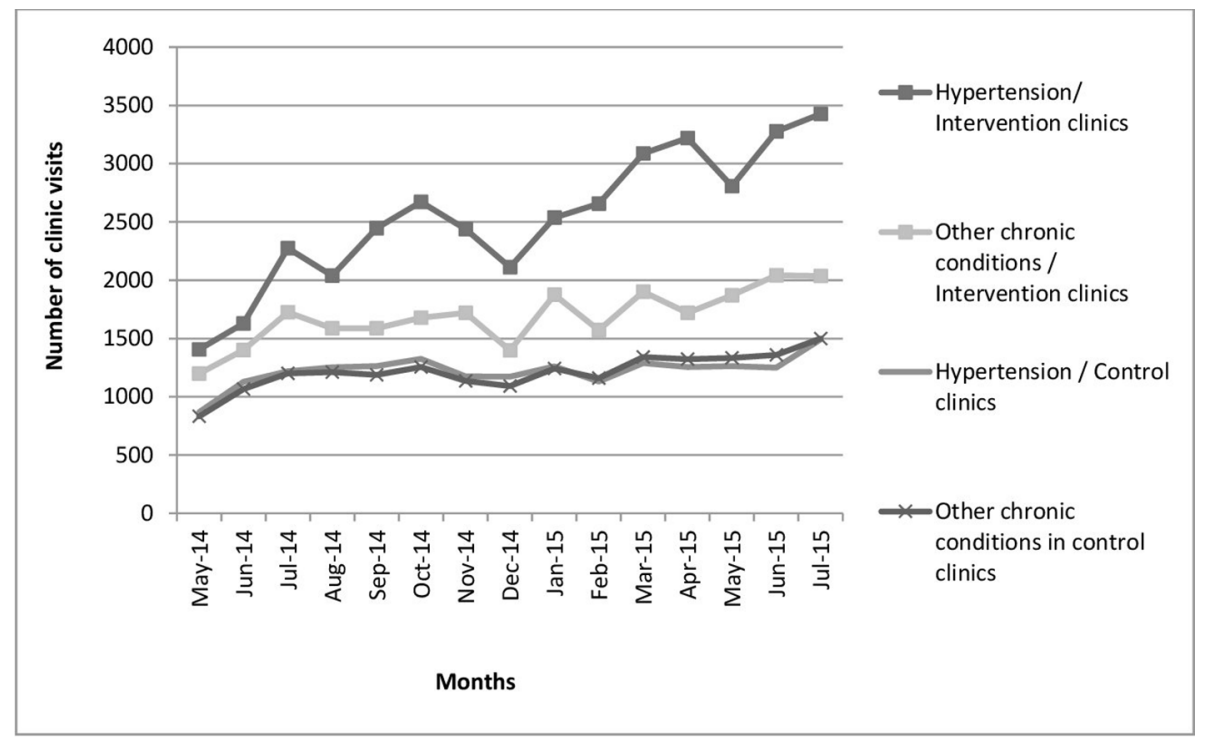

Figure 3 Number of monthly clinic visits by patients with hypertension and other chronic conditions in the control and intervention clinics.

a description of the state of the BP machines for different periods of the study.

Despite these challenges, there were signs of improvement in the provision of care. The LHWs were encouraged to support the nurses in identifying undiagnosed hypertension among patients attending for other reasons. In the intervention clinics, 760 patients without a diagnosis of hypertension were identified with high BP and half of them $(40 \%, 301$ individuals) subsequently received a diagnosis of hypertension during the 18 months. Data from patient exit interviews suggest that waiting times may have been reduced in the intervention clinics (table 4).

\section{DISCUSSION}

We aimed to improve the management of hypertension by providing extra support from LHWs to the nurses who are responsible for the management of chronic conditions in primary care clinics. We found no evidence of an improvement in the management of hypertension as a result of our intervention. However, we did find improvements in the functioning of the intervention clinics in a number of important ways, including patients keeping their appointments, and more patients with hypertension returning to the clinics.

This was a pragmatic trial, designed to test an intervention that was both affordable and sustainable in a sub-Saharan Africa context. Using the precis-2 tool, we (JG, MT) assessed that the trial had a score of 41 out of 45 , where 45 is the most pragmatic. ${ }^{28}$ We aimed to only provide those parts of an intervention which, if effective, could conceivably be funded by the South African Health budget. We provided some training for the nurses, and the implementation manager tried to assist in getting the BP machines

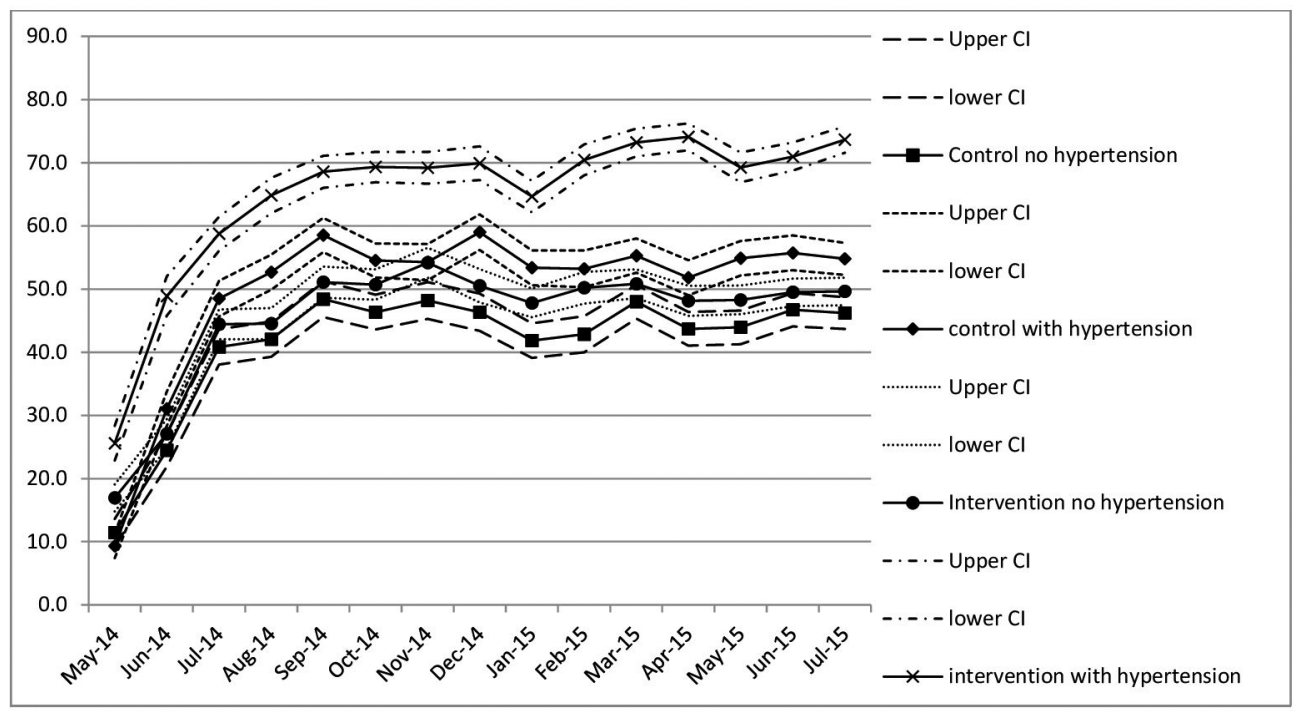

Figure 4 Percentage of patients who attend the clinic on their appointed day by month. 
Table 3 Description of the state of the BP machines from observations and interviews

\begin{tabular}{|c|c|c|}
\hline Study period & Intervention clinics & Control clinics \\
\hline \multirow[t]{2}{*}{ January to June 2014} & $\begin{array}{l}\text { Two clinics stopped using electronic } \\
\text { machines due to faulty cuffs and used } \\
\text { manual machines. } \\
\text { In one clinic the machine did not function } \\
\text { properly and readings were unreliable. }\end{array}$ & $\begin{array}{l}\text { Generally all electronic BP machines were } \\
\text { functioning well. } \\
\text { Although all cuffs were wearing out. }\end{array}$ \\
\hline & Cuffs for electronic machines provided to all clinic & \\
\hline July 2014 to March 2015 & $\begin{array}{l}\text { Cuffs for manual machines were still a } \\
\text { problem. } \\
\text { Electronic machines themselves began to } \\
\text { develop problems as a result of overuse. }\end{array}$ & Little information in this period \\
\hline April 2015 to August 2015 & $\begin{array}{l}\text { Problems with the electronic BP machines } \\
\text { increased (with the on/off button not working, } \\
\text { or the machine not clearing the data in } \\
\text { preparation for the next patient). } \\
\text { At the end of the period three of the four } \\
\text { intervention clinics had their machines sent } \\
\text { for repair. } \\
\text { Clinic managers had little hope of getting } \\
\text { them back soon. } \\
\text { Cuffs supplied by study had started wearing } \\
\text { out. }\end{array}$ & $\begin{array}{l}\text { Early in this phase one clinic sent its } \\
\text { machines for servicing, but it was not } \\
\text { returned by the end of study. } \\
\text { Two clinics doubted the accuracy of } \\
\text { readings and used a manual machine to } \\
\text { confirm a high reading. } \\
\text { Cuffs supplied by study had started wearing } \\
\text { out. }\end{array}$ \\
\hline
\end{tabular}

BP, blood pressure.

repaired using the normal systems. However, we did not supply extra BP machines. We did supply replacement cuffs for existing machines, but supplied these to both intervention and control clinics. Moreover, in keeping with the pragmatic nature of the trial, and to encourage clinic staff to feel ownership of the intervention, the ways in which the LHWs would support chronic disease care were decided separately in each clinic by the clinic staff.

The trial was based on a strong research platform provided by the HDSS which allowed us to carry out stratified random sample surveys and also to collect information on clinic activity. The population surveys, which measured the BP control of respondents who usually used the study clinics, were designed to identify a change in the numbers accessing treatment for hypertension as well as a change in BP control. However, this measure included those who might not have attending the clinic as regularly as they should have been, reducing our chances of identifying the effect of improved care on BP control among those who attended a clinic regularly. (Alternative study designs were not possible: existing clinic records were not sufficiently reliable; intervening to strengthen the current filing system would have reduced the pragmatic nature of the trial; and setting up a study measuring station for each clinic was not affordable.) Moreover, as there were only eight clinics in the HDSS we were limited in the number of possible clusters.

Through the implementation manager we were able to ensure fidelity to the planned intervention as well as sufficient flexibility to the local context. We were also careful to separate implementation and evaluation activities. It is possible that the activity of the trial contributed to improved performance in the control clinics. We had a data entry clerk in all the control clinics who collected information about clinic users and, inevitably, contributed to the management of the clinic files, and therefore relieved nurses of some routine tasks. However, we do not think this possible contamination was sufficient to reduce a difference between control and intervention outcomes.

The lack of effect in BP control may be due to the poor condition of the BP machines and cuffs, and that both the intervention and the control clinics were overwhelmed by a rapid increase in numbers of chronic patients. This increase was due both to the continuing roll-out of antiretrovirals

Table 4 Mean time in hours spent by patients with hypertension in clinics derived from exit interviews

\begin{tabular}{|c|c|c|c|c|c|c|}
\hline & \multicolumn{3}{|l|}{ Control } & \multicolumn{3}{|l|}{ Intervention } \\
\hline & $\begin{array}{l}\text { Phase } 1 \\
\text { March to July } \\
2014\end{array}$ & $\begin{array}{l}\text { Phase } 2 \\
\text { November to } \\
\text { March } 2015\end{array}$ & $\begin{array}{l}\text { Phase } 3 \\
\text { June to August } \\
2015\end{array}$ & $\begin{array}{l}\text { Phase } 1 \\
\text { March to July } \\
2014\end{array}$ & $\begin{array}{l}\text { Phase } 2 \\
\text { November to } \\
\text { March } 2015\end{array}$ & $\begin{array}{l}\text { Phase } 3 \\
\text { June to August } \\
2015\end{array}$ \\
\hline Mean (SD) & 3.67 (1.77) & $3.96(1.17)$ & 3.60 (1.29) & 3.30 (1.22) & 3.07 (0.99) & $2.41(1.16)$ \\
\hline $\mathrm{n}$ & 49 & 105 & 95 & 126 & 88 & 95 \\
\hline
\end{tabular}


for HIV and a hospital policy of referring outpatients back into primary care. In the intervention clinics, there was a further increase in patients with hypertension attending the clinic, most probably due to the intervention itself.

An earlier study of the ICDM initiative in the same clinics demonstrated that management of HIV was more effective than management of BP: less than $50 \%$ of the patients attending the clinic had controlled BP, nearly $90 \%$ of patients with HIV had a controlled CD4 count. ${ }^{9} 2829$ South Africa's HIV programme is vertically organised, with generous funding and a separate management structure, requiring more detailed reporting from primary care clinics. It may be that this also continued to distort the work in the clinics, despite attempts to integrate the provision of care; with no requirement to report patient outcomes for hypertension there is insufficient emphasis on improving clinical care. ${ }^{30}$

Systematic reviews of randomised trials have concluded that community health workers are effective in improving health and treatment outcomes, ${ }^{31}$ the included studies predominately focus on a single condition or health outcome (breast feeding, immunisation, TB cure rates), rather than the provision of integrated care. Moreover, the health outcomes measured are often those achieved by the community health worker alone, rather than outcomes requiring the contribution of other healthcare workers, as in this study. We found only one systematic review of studies looking at the effect of task shifting, which focused only on shifting prescribing from doctors to nurses. ${ }^{32}$ As far as we are aware, the Nkateko study was the first randomised controlled trial to assess the supportive role of LHWs in the management of hypertension in the context of clinic-based integrated chronic care.

\section{CONCLUSION}

Our intervention did not improve BP control, despite its success in increasing the number of patients with hypertension attending the clinic, as well as the number that attended on their appointed day. We believe that the study was compromised by the large and increasing demands on primary care, the dominance of the vertically funded HIV programme and the poor standards of equipment in clinics. However, as this study shows, adding additional human resources (even if readily available and relatively inexpensive) is unlikely to have an effect on health outcomes, without the necessary equipment to accurately measure BP, and sufficient clinical staff to treat the growing numbers of chronic patients. To be successful, task shifting interventions need to take account of all aspects of the patient encounter, and if possible other system-wide contextual changes (such as rapidly increasing patients). Our results, taken together with the existing evidence, suggest that LHWs can play an important role in supporting the management of hypertension.

\footnotetext{
Author affiliations

${ }^{1}$ Centre for Health Policy, Faculty of Health Sciences, School of Public Health, University of the Witwatersrand, Johannesburg, South Africa
}

${ }^{2}$ Faculty of Health Sciences, School of Public Health, University of the Witwatersrand, Johannesburg, South Africa

${ }^{3}$ Centre for Primary Care and Public Health, Barts and the London School of Medicine and Dentistry, Queen Mary University of London, London, UK ${ }^{4}$ MRC/Wits Rural Public Health and Health Transitions Research Unit (Agincourt), Faculty of Health Sciences, School of Public Health, University of the Witwatersrand, Johannesburg, South Africa

${ }^{6}$ Division of Epidemiology and Biostatistics, Faculty of Health Sciences, School of Public Health, University of the Witwatersrand, Johannesburg, South Africa ${ }^{5}$ Statistics and Epidemiology Unit, Warwick Medical School, University of Warwick, Coventry, UK

Contributors JG, MT: conceptualisation, overall oversight of the research, interpretation and analysis of data, drafting and revising the manuscript, and approval of final version. TC, SE, EM: interpretation and analysis of data, contributed to the drafting of the manuscript and approval of final version. FXFGO, CK: oversight of data collection, interpretation and analysis of data, contributed to the drafting of the manuscript and approval of final version. FL: management of data collection and implementation of research, interpretation and analysis of data, contributed to the drafting of the manuscript and approval of final version.

Funding The Nkateko study was funded by the UK Medical Research Council under the Global Alliance for Chronic Diseases (GACD) Programme.

Competing interests None declared.

Patient consent Obtained.

Ethics approval University of the Witwatersrand Human Research Ethics Committee (Medical), the University of Warwick Biomedical and Scientific Research Ethics Committee, and the Mpumalanga's Provincial Research and Ethics Committee.

Provenance and peer review Not commissioned; externally peer reviewed.

Data sharing statement The Stata dataset containing the baseline and end of intervention surveys are available in the Warwick Research Archive Portal (WRAP) repository,

Open Access This is an Open Access article distributed in accordance with the terms of the Creative Commons Attribution (CC BY 4.0) license, which permits others to distribute, remix, adapt and build upon this work, for commercial use, provided the original work is properly cited. See: http://creativecommons.org/ licenses/by/4.0/

(C) Article author(s) (or their employer(s) unless otherwise stated in the text of the article) 2018. All rights reserved. No commercial use is permitted unless otherwise expressly granted.

\section{REFERENCES}

1. World Health Organization. Global status report on noncommunicable diseases. Geneva, Switzerland 2014

2. Evans D. Ten years on ART - where to now? S Afr Med J 2013;103:229-31.

3. Lloyd-Sherlock P, Beard J, Minicuci N, et al. Hypertension among older adults in low- and middle-income countries: prevalence, awareness and control. Int J Epidemiol 2014;43:116-28.

4. Mayosi BM, Flisher AJ, Lalloo UG, et al. Health in South Africa 4 The burden of non-communicable diseases in South Africa. Lancet 2009;374:934-47.

5. Gómez-Olivé FX, Thorogood M, Clark B, et al. Self-reported health and health care use in an ageing population in the Agincourt subdistrict of rural South Africa. Glob Health Action 2013:6:19305-92.

6. Mahomed OH, Asmall S, Freeman M. An integrated chronic disease management model: a diagonal approach to health system strengthening in South Africa. $J$ Health Care Poor Underserved 2014;25:1723-9.

7. Mahomed O, Asmall S. Development and implementation of an integrated chronic disease model in South Africa: lessons in the management of change through improving the quality of clinical practice. Int J Integr Care 2015;15:1-13.

8. Ameh S, Klipstein-Grobusch K, D'ambruoso L, et al. Quality of integrated chronic disease care in rural South Africa: user and provider perspectives. Health Policy Plan 2017;32:257-66.

9. Ameh S, Klipstein-Grobusch K, D'ambruoso L, et al. Quality of integrated chronic disease care in rural South Africa: user and provider perspectives. Health Policy Plan 2016;32:czw118.

10. Fulton BD, Scheffler RM, Sparkes SP, et al. Health workforce skil mix and task shifting in low income countries: a review of recent evidence. Hum Resour Health 2011;9:1. 
11. Hamer DH, Brooks ET, Semrau K, et al. Quality and safety of integrated community case management of malaria using rapid diagnostic tests and pneumonia by community health workers. Pathog Glob Health 2012;106:32-9.

12. Heunis JC, Wouters E, Norton WE, et al. Patient- and delivery-level factors related to acceptance of HIV counseling and testing services among tuberculosis patients in South Africa: a qualitative study with community health workers and program managers. Implement Sci $2011 ; 6: 27$.

13. Mubi M, Janson A, Warsame $M$, et al. Malaria rapid testing by community health workers is effective and safe for targeting malaria treatment: randomised cross-over trial in Tanzania. PLoS One 2011;6:e19753.

14. Harvey SA, Jennings L, Chinyama M, et al. Improving community health worker use of malaria rapid diagnostic tests in Zambia: package instructions, job aid and job aid-plus-training. Malar $J$ 2008;7:160.

15. Atkins $\mathrm{S}$, Lewin $\mathrm{S}$, Jordaan $\mathrm{E}$, et al. Lay health worker-supported tuberculosis treatment adherence in South Africa: an interrupted time-series study. Int J Tuberc Lung Dis 2011;15:84-9.

16. Chang AH, Polesky A, Bhatia G. House calls by community health workers and public health nurses to improve adherence to isoniazid monotherapy for latent tuberculosis infection: a retrospective study. BMC Public Health 2013;13:894.

17. Gaziano TA, Bertram M, Tollman SM, et al. Hypertension education and adherence in South Africa: a cost-effectiveness analysis of community health workers. BMC Public Health 2014;14:240.

18. Kahn K, Collinson MA, Gómez-Olivé FX, et al. Profile: Agincourt health and socio-demographic surveillance system. Int J Epidemiol 2012;41:988-1001.

19. Collinson MA. Striving against adversity: the dynamics of migration, health and poverty in rural South Africa. Glob Health Action 2010;3:5080

20. Thorogood M, Goudge J, Bertram M, et al. The Nkateko health service trial to improve hypertension management in rural South Africa: study protocol for a randomised controlled trial. Trials $2014 ; 15: 435$
21. Hooper R, Bourke L. Cluster randomised trials with repeated cross sections: alternatives to parallel group designs. BMJ 2015;350:h2925.

22. Seedat YK, Rayner BL. Southern African Hypertension Society. South African hypertension guideline 2011. S Afr Med J 2011;102:60-83.

23. Kabudula CW, Clark BD, Gómez-Olivé FX, et al. The promise of record linkage for assessing the uptake of health services in resource constrained settings: a pilot study from South Africa. BMC Med Res Methodol 2014;14:71.

24. Clark SJ, Gómez-Olivé FX, Houle B, et al. Cardiometabolic disease risk and HIV status in rural South Africa: establishing a baseline. BMC Public Health 2015;15:135.

25. Hayes RJ, Bennett S. Simple sample size calculation for clusterrandomized trials. Int J Epidemiol 1999;28:319-26.

26. Pronyk PM, Hargreaves JR, Kim JC, et al. Effect of a structural intervention for the prevention of intimate-partner violence and HIV in rural South Africa: a cluster randomised trial. Lancet 2006;368:1973-83.

27. Murray DM, Varnell SP, Blitstein JL. Design and analysis of grouprandomized trials: a review of recent methodological developments. Am J Public Health 2004;94:423-32.

28. Loudon K, Treweek S, Sullivan F, et al. The PRECIS-2 tool: designing trials that are fit for purpose. BMJ 2015;350:h2147.

29. Mahomed $\mathrm{OH}$, Asmall S. Development and implementation of an integrated chronic disease model in South Africa: lessons in the management of change through improving the quality of clinical practice. Int J Integr Care 2015;15.

30. Kawonga M, Blaauw D, Fonn S. Aligning vertical interventions to health systems: a case study of the HIV monitoring and evaluation system in South Africa. Health Res Policy Syst 2012;10:2.

31. Lewin S, Munabi-Babigumira S, Glenton C, et al. Lay health workers in primary and community health care for maternal and child health and the management of infectious diseases. Cochrane Database Syst Rev 2010:CD004015.

32. Weeks G, George J, Maclure K, et al. Non-medical prescribing versus medical prescribing for acute and chronic disease management in primary and secondary care. Cochrane Database Syst Rev 2016;11:Cd011227. 